\title{
Kondisi lingkungan fisik dan lama waktu bermain di luar rumah dengan kegemukan pada anak prasekolah
}

Built environment and outdoor playing time with obesity in preschool children

\section{Ika Agustina ${ }^{1}$, M Made Alit Gunawan², Madarina Julia ${ }^{3}$}

\author{
PKPU Human Initiative Balikpapan \\ 2 Jurusan Gizi Politeknik Kesehatan Kementerian Kesehatan Yogyakarta \\ ${ }^{3}$ Departemen Ilmu Kesehatan Anak Fakultas Kedokteran Universitas Gadjah Mada/Rumah Sakit Umum Pusat Dr. Sardjito
}

\begin{abstract}
Background: The prevalence of childhood obesity in Yogyakarta Municipality has increased in recent years. The built environment of which are not designed properly may limit the time for children's outdoor activity. Objective: This study tried to investigate the links between parents perceptions of their built environment with outdoor playing time and obesity among preschool children in Yogyakarta Municipality. Method: This is a case-control study. Cases were identified as obese preschoolers (Z score based on $W / H>2 S D$ ) and controls were children who were not obese ( $Z$ score based on $W / H \leq 2 S D$ ) and matched by sex and age. Data were collected in the Yogyakarta Municipality. Samples were selected using multistage sampling method. The sample of cases and controls were 101 people (1: 1), respectively. conditional logistic regression statistical tests were performed to identify the risk factors for preschool obesity. Results: Children who did not play outdoors enough time were at higher risk of becoming obese $(O R=2,27, C I(1,14-4,62))$; Built environment seems to be a modifier for outdoor playing time that will impact the odds of obesity among preschool children. Conclusion: Preschool children who played outdoor less than 2 hours had a higher risk of becoming obese. Outdoor playing time was associated with built environment.
\end{abstract}

KEY WORDS: built environment; outdoor playing time; obesity; preschool

\begin{abstract}
ABSTRAK
Latar belakang: Prevalensi kegemukan pada anak di Kota Yogyakarta sejak tahun 2007 tidak mengalami penurunan berarti. Salah satu penyebabnya adalah semakin menurunnya lama waktu bermain anak di luar rumah akibat dari kondisi lingkungan fisik di masyarakat yang tidak mendukung. Tujuan: Menganalisis kondisi lingkungan fisik dan lama waktu bermain di luar rumah dengan kegemukan pada anak prasekolah di Kota Yogyakarta. Metode: Penelitian ini merupakan penelitian kasus kontrol. Kasus adalah anak prasekolah yang diidentifikasi gemuk (Z score berdasarkan $\mathrm{BB} / \mathrm{TB}>2 \mathrm{SD}$ ), kontrol adalah anak yang tidak gemuk ( $Z$ score berdasarkan $\mathrm{BB} / \mathrm{TB} \leq 2 \mathrm{SD}$ ) dengan matching usia dan jenis kelamin. Lokasi penelitian adalah kota Yogyakarta dengan pemilihan sampel menggunakan metode multistage sampling. Sampel kasus dan kontrol masing-masing kelompok adalah 101 orang (1:1). Uji statistik conditional logistic regression dilakukan untuk mengidentifikasi variabel yang merupakan faktor risiko. Hasil: Anak yang bermain di luar rumah kurang dari 2 jam berisiko lebih tinggi menjadi gemuk ( $O R=2,27$; CI=1,14-4,62). Kondisi lingkungan fisik menjadi efek modifier pada lama waktu bermain di luar rumah yang kemudian meningkatkan risiko kegemukan anak. Simpulan: Anak prasekolah yang tidak memiliki cukup waktu bermain di luar rumah memiliki risiko menjadi gemuk lebih tinggi. Lama waktu bermain anak dipengaruhi oleh kondisi lingkungan fisik di lingkungannya.
\end{abstract}

KATA KUNCI: lingkungan fisik; bermain di luar rumah; kegemukan; anak prasekolah

\section{PENDAHULUAN}

Kegemukan pada anak telah menjadi ancaman di seluruh dunia $(1,2)$, termasuk di Indonesia yang menunjukkan angka kejadian terus meningkat setiap tahunnya (3). Faktor genetik tidak lagi menjadi satu-

Korespondensi: Ika Agustina, PKPU Human Initiative Balikpapan; Jl. Soekarno Hatta no 12 RT 3 KM 2 Muara Rapak Balikpapan Utara, e-mail: ikaagustina. nutrition@mail.ugm.ac.id 
satunya penyebab kegemukan pada anak (4). Adanya perubahan pola asuh orang tua yang dipengaruhi faktor lingkungan diketahui meningkatkan risiko kegemukan pada anak (5). Orang tua saat ini cenderung lebih banyak memberikan makanan yang tinggi lemak karena akses ketersediaan makanan siap saji yang lebih mudah dan lebih disukai oleh anak-anak. Sementara itu, pergerakan anak di luar rumah semakin terbatas karena kekhawatiran orang tua yang dikaitkan dengan fasilitas dan kondisi untuk bermain di luar rumah yang dianggap kurang memadai (6-8).

Penurunan aktivitas fisik pada anak diikuti dengan peningkatan perilaku sedentari telah menjadi fenomena yang cukup lazim saat ini. Disebutkan bahwa tidak seperti masa kecil orang tuanya, saat ini hanya sedikit anak-anak yang dapat bermain di luar rumah dengan bebas dalam waktu lama (9). Kondisi ini dipengaruhi oleh keamanan lingkungan dan social kohesion di tempat anak-anak bermukim (10-12) dan ketersediaan fasilitas untuk bermain seperti halaman, taman bermain, dan playground (13-15). Bermain di luar rumah merupakan salah satu kontributor aktivitas fisik anak prasekolah (14) dan penting untuk proses belajar dan perkembangan anak (16).

Kegemukan menjadi pemandangan yang tidak asing di Daerah Istimewa Yogyakarta (DIY), melihat prevalensinya telah berada di atas angka rata-rata nasional (3)ERROR: requested citation index out of range. Jumlah anak prasekolah yang gemuk juga terlihat terus bertambah setiap tahunnya dengan angka tertinggi berada di Kota Yogyakarta $(17,18)$ ERROR: requested citation index out of range. Sebagai salah satu kota ternyaman (the most liveable city) di Indonesia dan kota berpredikat "Kota Layak Anak" $(19,20)$ ERROR: requested citation index out of range seharusnya angka kegemukan di Kota Yogyakarta dapat dikendalikan karena lingkungan yang nyaman dan ramah anak akan mendukung anak untuk bermain di luar rumah lebih aktif. Namun pada kenyataannya, jumlah angka kegemukan dan obesitas pada orang dewasa maupun anak masih terus bertambah. Berdasarkan latar belakang tersebut, peneliti tertarik untuk melakukan penelitian untuk mengetahui hubungan antara kondisi lingkungan fisik dan lama waktu bermain di luar rumah dengan kegemukan pada anak prasekolah di Kota Yogyakarta.

\section{BAHAN DAN METODE}

Penelitian ini berjenis observasional dengan rancangan penelitian kasus kontrol. Populasi dari penelitian ini adalah anak usia 3-5 tahun yang bersekolah PAUD (Pendidikan Anak Usia Dini) di Kota Yogyakarta. Waktu penelitian untuk pengambilan data dilakukan pada bulan Juni-Oktober 2015. Metode pengambilan sampel menggunakan teknik multistage sampling dan penentuan sekolah PAUD yang akan digunakan dalam skrining status gizi menggunakan metode Probability Proportional to Size (PPS). Metode PPS dipilih karena lokasi Kota Yogyakarta yang cukup luas dengan jumlah sekolah PAUD yang cukup besar. Langkah awal dari metode ini adalah menghitung interval sampling dengan cara membagi total jumlah siswa PAUD usia 2-6 tahun (3574 anak) dengan jumlah klaster yang disepakati yaitu 45 sesuai dengan jumlah kelurahan di Kota Yogyakarta. Hasil dari penambahan nilai interval sampling secara kumulatif tersebut digunakan sebagai pemilihan sekolah PAUD yang akan dipilih sebagai lokasi skrining status gizi. Jumlah sekolah PAUD yang diskrining minimal adalah 45 sekolah. Skrining status gizi mengikutsertakan 1.728 anak usia 3-5 tahun dari 53 sekolah PAUD di Kota Yogyakarta. Subjek kasus dipilih secara purposive sampling yang memenuhi kriteria inklusi. Perhitungan besar sampel menggunakan rumus untuk penelitian kasus kontrol berpasangan (21) dengan tingkat kepercayaan $95 \%(\mathrm{Z} \alpha)$; Z $\beta$ sebesar 1,64; dan odds ratio sebesar 0,5 untuk kualitas lingkungan (22); 0,41 untuk kepemilikan halaman (23); dan 3,84 untuk lama bermain di luar rumah (24). Jumlah sampel minimal yang harus dipenuhi adalah 182 orang ( 91 orang kelompok kasus dan 91 orang kelompok kontrol).

Kasus ( $\mathrm{n}=101)$ dipilih dari subjek yang memiliki Z-score BB/TB > 2 SD berdasarkan World Health Organization (WHO) 2005, tinggal bersama ibu kandung, dan orang tua bersedia mengikuti penelitian yang dinyatakan dengan mengisi inform consent. Kriteria eksklusi subjek penelitian ini adalah anak yang memiliki edema atau ascites, berkebutuhan khusus atau merupakan siswa full day. Kontrol $(\mathrm{n}=101)$ adalah subjek yang memiliki berat badan dengan status gizi normal $(-2<\mathrm{Z}$-score $\mathrm{BB} / \mathrm{TB}<2)$ dengan penyetaraan berdasarkan usia dan jenis kelamin. Penelitian ini telah 
mendapatkan Surat Kelaikan Etik (Ethical Approval) dengan nomor KE/FK/747/EC/2015 dari Komisi Etik Fakultas Kedokteran Universitas Gadjah Mada tanggal 24 Juni 2015 dan persetujuan setelah penjelasan oleh seluruh orang tua subjek.

Pengukuran antropometri saat skrining status gizi di sekolah subjek dilakukan oleh tim enumerator berlatar belakang S1 Gizi yang telah mendapatkan pelatihan sebelumnya. Data tinggi badan dan berat badan anak dikumpulkan dengan melakukan pengukuran tinggi badan menggunakan microtoise dengan ketelitian $0,1 \mathrm{~cm}$ dan berat badan menggunakan timbangan badan digital dengan ketelitian $0,1 \mathrm{~kg}$ yang telah dikalibrasi oleh Badan Metrologi. Anak diukur dengan pakaian seragam seminimal mungkin dan tanpa menggunakan alas kaki. Status gizi dihitung dengan menggunakan software WHO Anthro dan untuk analisis statistik maka status gizi subjek dikategorikan menjadi gemuk jika nilai $z$-score $>2$ dan normal jika z-score $\geq-2$ SD sampai $\leq 2$ SD.

Kondisi lingkungan fisik dan lama waktu bermain di luar rumah ditanyakan langsung kepada ibu subjek sebagai responden oleh enumerator. Kuesioner untuk mengukur kondisi lingkungan fisik terdiri dari 14 item pertanyaan yang berasal dari modifikasi kuesioner Preschool-aged Children's Physical Activity Questionnaire (Pre-PAQ) (25) dan Neighbourhood Environment Walkability Score Youth for Parents (NEWS Y-for Parent) (26). Kuesioner ini telah divalidasi dengan nilai cronbach alpha 0,70 . Kondisi lingkungan fisik yang diukur berupa ketersediaan halaman di rumah (1 pertanyaan), persepsi ibu terhadap kepadatan penduduk (3 pertanyaan), dan kondisi lingkungan fisik (10 pertanyaan terkait dengan ketersediaan jalan, lalu lintas, pemanfaatan lahan dan fasilitas bermain).

Ketersediaan halaman akan dikategorikan menjadi punya (koding 0) jika memiliki halaman di rumah atau di sekitar rumahnya dan tidak punya (koding 1) jika tidak terdapat halaman di sekitar rumah. Skor persepsi ibu terhadap kondisi lingkungan fisik dan kepadatan penduduk dihitung berdasarkan jumlah total skor dari komponen yang ditanyakan kemudian dikategorikan menjadi 2 berdasarkan cut-off median (positif dan negatif) (27). Kepadatan penduduk dilihat dari persepsi ibu terhadap jenis-jenis hunian yang ada di sekitar lingkungan rumahnya dan dikategorikan menjadi lingkungan padat jika total skor jawaban ibu $\geq 32$ (koding 1) dan lingkungan tidak padat jika total skor jawaban ibu $<32$ (koding 0). Persepsi ibu terhadap kondisi lingkungan fisik dikategorikan menjadi persepsi positif jika total skor $\geq$ 14,35(koding 0) dan persepsi negatif jika total skor < 14,35(koding 1).

Lama waktu bermain di luar rumah diukur berdasarkan kuesioner Preschool-aged Children's Physical Activity Questionnaire (Pre-PAQ). Lama waktu bermain di luar akan dikategorikan menjadi 2 kategori yaitu di bawah 2 jam atau di atas sama dengan 2 jam (14). Lama tahun pendidikan orang tua digunakan sebagai indikator status sosial ekonomi $(28,29)$ dengan kategori rendah/menengah (di bawah atau sama dengan SMA) dan tinggi (di atas atau sama dengan diploma).

Uji Chi-Square digunakan untuk melihat distribusi frekuensi karakteristik subjek penelitian dan status kegemukan subjek. Uji bivariat antara variabel kondisi lingkungan fisik dan lama waktu bermain dengan kegemukan menggunakan analisis $M c$-Nemar. Uji statistik conditional logistic regression dilakukan untuk mengetahui variabel yang menjadi faktor risiko dominan pada kegemukan anak prasekolah dengan memperhitungkan penyetaraan usia dan jenis kelamin.

\section{HASIL}

\section{Karakteristik subjek}

Subjek penelitian berjumlah 202 anak usia prasekolah yang terdiri dari 101 subjek kelompok gemuk dan 101 subjek kelompok tidak gemuk (anak berstatus gizi normal). Penelitian ini melakukan penyetaraan secara berpasangan pada kelompok kasus dan kontrol berdasarkan usia dan jenis kelamin. Usia rerata kelompok gemuk adalah 49,8 $(\mathrm{SD} \pm 6,1)$ bulan dan rerata usia pada kelompok tidak gemuk adalah 49,6 (SD $\pm 6,5)$ bulan. Rata-rata lama waktu anak di sekolah adalah 2,74 (SD $\pm 0,62)$ jam.

Rerata usia ibu yang menjadi responden dari penelitian ini adalah 33,8 $(\mathrm{SD} \pm 5,3)$ tahun. Lama tahun ibu tinggal di lingkungan rata-rata adalah 9,34 $(\mathrm{SD} \pm 9,67)$ tahun. Sebagian besar ibu yang menjadi responden adalah ibu yang bekerja $(67,33 \%)$ dengan jenis pekerjaan terbanyak 
adalah karyawan swasta (33,17\%) dan wiraswasta $(24,26 \%)$. Jenis pekerjaan ayah subjek mulai dari yang terbanyak adalah karyawan swasta $(50,75 \%)$, wiraswasta $(32,34 \%)$, lainnya $(8,46 \%)$ dan pegawai negeri $(7,96 \%)$. Karakteristik subjek penelitian dapat dilihat pada Tabel 1.

Tabel 1. Karakteristik subjek penelitian

\begin{tabular}{|c|c|c|c|c|}
\hline \multirow[t]{2}{*}{ Karakteristik } & $\begin{array}{c}\text { Gemuk } \\
(n=101)\end{array}$ & $\begin{array}{c}\text { Tidak } \\
\text { gemuk } \\
(n=101)\end{array}$ & $\mathbf{X}^{2}$ & \multirow[t]{2}{*}{$\mathbf{p}$} \\
\hline & $(\%)$ & $(\%)$ & & \\
\hline \multicolumn{5}{|l|}{ Status bekerja orang tua } \\
\hline Kedua orang tua bekerja & 70 & 62 & 1,42 & 0,23 \\
\hline Salah satu bekerja & 30 & 38 & & \\
\hline \multicolumn{5}{|l|}{ Pendidikan ayah } \\
\hline Tinggi & 63 & 62 & 0,06 & 0,81 \\
\hline Rendah/ Menengah & 37 & 39 & & \\
\hline \multicolumn{5}{|l|}{ Pendidikan ibu } \\
\hline Tinggi & 69 & 62 & 1,08 & 0,30 \\
\hline Rendah/ Menengah & 31 & 38 & & \\
\hline \multicolumn{5}{|l|}{ Status pernikahan orangtua } \\
\hline Single parents & 9 & 11 & 0,22 & 0,64 \\
\hline Orang tua lengkap & 91 & 89 & & \\
\hline \multicolumn{5}{|l|}{ Kriteria tempat tinggal } \\
\hline Kota & 94 & 92 & 0,31 & 0,58 \\
\hline Desa & 6 & 8 & & \\
\hline \multicolumn{5}{|l|}{ Kriteria hunian } \\
\hline Bukan perkampungan & 22 & 17 & 0,79 & 0,37 \\
\hline Perkampungan & 78 & 83 & & \\
\hline \multicolumn{5}{|l|}{ Kepemilikan rumah } \\
\hline Bukan rumah pribadi & 53 & 61 & 1,29 & 0,26 \\
\hline Rumah pribadi & 48 & 40 & & \\
\hline \multicolumn{5}{|l|}{ Ketersediaan halaman } \\
\hline Tidak punya & 12 & 14 & 0,18 & 0,67 \\
\hline Punya & 89 & 87 & & \\
\hline \multicolumn{5}{|c|}{ Persepsi terhadap lingkungan fisik ${ }^{1}$} \\
\hline Negatif & 51 & 50 & 0,02 & 0,89 \\
\hline Positif & 50 & 51 & & \\
\hline \multicolumn{5}{|l|}{ Kepadatan penduduk $^{2}$} \\
\hline Padat & 52 & 48 & 0,32 & 0,57 \\
\hline Tidak padat & 49 & 53 & & \\
\hline \multicolumn{5}{|c|}{ Lama waktu bermain di luar rumah } \\
\hline Main $<2$ jam & 79 & 65 & 4,74 & 0,03 \\
\hline Main $\geq 2$ jam & 22 & 36 & & \\
\hline
\end{tabular}

Signifikan dengan uji Chi-Squared $\mathrm{p}<0,05$;

${ }^{1}$ Persepsi terhadap lingkungan fisik dinilai berdasarkan persepsi ibu pada ketersediaan fasilitas bermain, kondisi jalan (street connectivity), pemanfaatan lahan (land used), kepadatan lalu lintas (traffic), fasilitas untuk pejalan kaki, dan keamanan lingkungan: positif (skor $\geq 14,36$ ) dan negatif (skor $<14,36$ ); ${ }^{2}$ Kepadatan penduduk dilihat dari persepsi ibu terhadap jenis-jenis hunian yang ada di sekitar lingkungan rumahnya: padat (skor $\geq 32$ ); tidak padat $($ skor $<32$ ).
Rata-rata waktu bermain anak di luar rumah adalah 77,0 (SD \pm 47,9) menit untuk kelompok anak gemuk dan 93,3 $(\mathrm{SD} \pm 58,2)$ menit untuk kelompok anak tidak gemuk. Hubungan antara kondisi lingkungan fisik dilihat melalui ketersediaan halaman, persepsi ibu pada kondisi lingkungan fisik dan kepadatan penduduk dengan kegemukan. Hasil analisis bivariat antara variabelvariabel tersebut dapat dilihat pada Tabel 2.

Hasil uji bivariat memperlihatkan lama waktu bermain di bawah 2 jam akan meningkatkan risiko kegemukan pada anak prasekolah $(\mathrm{OR}=2,27$; $\mathrm{CI}=1,12$ 4,62 ). Satu-satunya variabel kondisi lingkungan fisik yang memberikan kecenderungan meningkatkan risiko kegemukan adalah kepadatan penduduk $(\mathrm{OR}=1,17$; $\mathrm{CI}=$ 0,67-2,01). Faktor risiko dominan dapat dilihat melalui hasil analisis multivariat dapat dilihat pada Tabel 3.

Model 1 dibangun untuk mengetahui pengaruh lama waktu bermain anak pada kegemukan dengan mengontrol keseluruhan variabel kondisi lingkungan fisik sedangkan model 2 sampai dengan 5 dibangun untuk mengetahui pengaruh lama waktu bermain anak di luar rumah dan kegemukan dengan mengontrol masing-masing variabel kondisi lingkungan fisik. Hasil uji multivariat menunjukkan bahwa lama waktu bermain anak di luar rumah merupakan faktor risiko dominan kegemukan pada anak prasekolah.

\section{BAHASAN}

Pada kedua kelompok tidak menunjukkan adanya perbedaan pada status sosial ekonomi yang dilihat dari pekerjaan dan pendidikan orang tua. Kondisi ini sesuai dengan hasil penelitian seselumnya (30) bahwa sosial ekonomi seperti pendidikan dan pekerjaan orang tua tidak berhubungan dengan status kegemukan anak prasekolah di Kota Yogyakarta. Penelitian lain menjelaskan bahwa hubungan antara tingkat sosial ekonomi keluarga tidak selalu linear dengan status gizi anak (31).

Hasil analisis untuk lama waktu bermain di luar rumah dan kegemukan menunjukkan anak-anak yang bermain di luar rumah kurang dari 2 jam menaikkan risiko menjadi gemuk hingga 2,27 kali lebih tinggi dibandingkan anak yang bermain di luar rumah di atas atau sama dengan 2 jam. Hasil ini sesuai dengan 
Tabel 2. Hubungan kondisi lingkungan fisik dan lama waktu bermain dengan kegemukan

\begin{tabular}{|c|c|c|c|c|c|c|}
\hline \multicolumn{7}{|l|}{ Ketersediaan halaman } \\
\hline \multirow{2}{*}{ Kelompok gemuk } & \multicolumn{3}{|c|}{ Kelompok tidak gemuk } & \multirow[b]{2}{*}{ OR } & \multirow[b]{2}{*}{$\mathrm{CI}$} & \multirow[b]{2}{*}{$\mathrm{p}$} \\
\hline & Tidak ada & Ada & Total & & & \\
\hline Tidak ada & 1 & 11 & 12 & \multirow{3}{*}{0,85} & \multirow{3}{*}{$0,38-1,89$} & \multirow{3}{*}{0,85} \\
\hline Ada & 13 & 76 & 89 & & & \\
\hline Total & 14 & 87 & 101 & & & \\
\hline \multicolumn{7}{|c|}{ Persepsi terhadap lingkungan fisik } \\
\hline \multirow{2}{*}{ Kelompok gemuk } & \multicolumn{3}{|c|}{ Kelompok tidak gemuk } & & & \\
\hline & Negatif & Positif & Total & OR & $\mathrm{CI}$ & $\mathrm{p}$ \\
\hline Negatif (total skor < 14,36) & 28 & 22 & 50 & & & \\
\hline Positif (total skor $\geq 14,36$ ) & 23 & 28 & 51 & 0,96 & $0,53-1,72$ & 1,00 \\
\hline Total & 51 & 50 & 101 & & & \\
\hline Kepadatan penduduk & \multicolumn{3}{|c|}{ Kelompok tidak gemuk } & & & \\
\hline Kelompok gemuk & Tidak padat & padat & Total & OR & $\mathrm{CI}$ & $\mathrm{p}$ \\
\hline Tidak padat (Skor < 32) & 24 & 28 & 55 & & \multirow{3}{*}{$0,67-2,01$} & \multirow{3}{*}{0,68} \\
\hline Padat (skor $\geq 32$ ) & 24 & 25 & 46 & 1,17 & & \\
\hline Total & 48 & 53 & 101 & & & \\
\hline $\begin{array}{l}\text { Lama waktu bermain di } \\
\text { luar rumah }\end{array}$ & \multicolumn{3}{|c|}{ Kelompok tidak gemuk } & & & \\
\hline Kelompok gemuk & Main $<2$ jam & Main $\geq 2$ jam & Total & OR & $\mathrm{CI}$ & $\mathrm{p}$ \\
\hline Main $<2$ jam & 54 & 25 & 79 & 2,27 & \multirow{3}{*}{$1,14-4,52$} & \multirow[t]{3}{*}{0,03} \\
\hline Main $\geq 2$ jam & 11 & 11 & 22 & & & \\
\hline Total & 65 & 36 & 101 & & & \\
\hline
\end{tabular}

Tabel 3. Uji multivariat kondisi lingkungan fisik dan sosial serta lama waktu bermain di luar rumah dengan kegemukan

\begin{tabular}{|c|c|c|c|c|c|}
\hline & Model 1 & Model 2 & Model 3 & Model 4 & Model 5 \\
\hline \multirow[t]{2}{*}{ Lama waktu bermain di luar rumah } & $2,44 *$ & $2,42 *$ & $2,27 *$ & $2,29 *$ & $2,27^{*}$ \\
\hline & $(1,16-5,13)$ & $(1,17-5,02)$ & $(1,12-4,63)$ & $(1,11-4,71)$ & $(1,12-4,62)$ \\
\hline \multirow[t]{2}{*}{ Ketersediaan halaman } & 1,03 & & & 1,03 & \\
\hline & $(0,44-2,47)$ & & & $(0,44-2,34)$ & \\
\hline \multirow[t]{2}{*}{ Persepsi pada kondisi lingkungan fisik } & 1,01 & & 1,01 & & \\
\hline & $(0,56-1,87)$ & & $(0,55-1,84)$ & & \\
\hline \multirow[t]{2}{*}{ Kepadatan penduduk } & 1,33 & 1,33 & & & \\
\hline & $(0,75,2,34)$ & $(0,75-2,34)$ & & & \\
\hline $\mathrm{N}$ & 202 & 202 & 202 & 202 & 202 \\
\hline $\mathrm{R}^{2}(\%)$ & $4,7 \%$ & $4,7 \%$ & $4 \%$ & $4 \%$ & $4 \%$ \\
\hline
\end{tabular}

*Signifikan dengan uji Conditional Logistic Regression $(\mathrm{p}<0,05)$

penelitian-penelitian yang dilakukan sebelumnya yang berpendapat bahwa lama waktu bermain di luar rumah berhubungan negatif dengan kegemukan $(31,32)$. Anak yang bermain di luar rumah lebih lama akan memiliki status kesehatan yang lebih baik (33).

Di antara ketiga variabel lingkungan fisik hanya variabel kepadatan penduduk yang menunjukkan kecenderungan untuk meningkatkan risiko kegemukan sebesar 17\%. Menurut hasil penelitian sebelumnya (34) lingkungan yang tidak padat penduduk menunjukkan kebanyakan keluarga yang tinggal di daerah tersebut memiliki pendapatan yang tinggi. Anak dari keluarga dengan status ekonomi tinggi cenderung gemuk dan memiliki aktivitas fisik yang rendah (35). Persepsi orang tua terhadap lingkungan fisik tidak berpengaruh pada kegemukan anak prasekolah di Kota Yogyakarta hasil yang sama juga di temukan pada anak di Amerika Latin (36). Penelitian yang dilakukan di Melbourne dan 
Kota Suburban di Amerika Serikat menunjukkan bahwa persepsi orang tua terhadap lingkungan fisik (keamanan dan kenyamanan) berperan dalam pembatasan aktivitas bermain anak di luar rumah $(11,37)$.

Hasil analisis mulitivariat menunjukkan lama waktu bermain sebagai faktor risiko dominan pada kegemukan anak prasekolah. Temuan ini sejalan dengan penelitian yang dilakukan pada anak-anak TK di kota Bogor yang menyatakan lama waktu bermain akan meningkatkan risiko kegemukan (24). Hasil analisis multivariat memperlihatkan risiko kegemukan akan meningkat pada anak yang bermain di luar rumah di bawah 2 jam dengan mengontrol kepadatan penduduk. Penelitian lain (38) menyatakan bahwa kondisi lingkungan fisik dan sosial tidak mempengaruhi kenaikan BMI pada orang dewasa tetapi mempengaruhi aktivitas fisik. Hal ini dapat dijelaskan karena orang tua yang menganggap lingkungannya tidak aman untuk anaknya bermain akan membatasi pergerakan anak (39) dan kemudian meningkatkan risiko kegemukan pada anak $(12,40,41)$. Kepadatan penduduk yang tinggi akan menurunkan lama waktu bermain anak karena kebanyakan orang tua khawatir terhadap kepadatan lalu lintas dan kehadiran orang asing $(11,42)$. Kekhawatiran orang tua yang tinggal di area padat penduduk menyebabkan adanya pembatasan waktu bermain di luar rumah.

Kelemahan pertama dari penelitian ini adalah bias recall dalam pengambilan data lama waktu bermain anak karena tidak menghitung waktu bermain anak saat di sekolah atau saat tidak dipantau oleh orang tua. Namun, penelitian ini mengontrol aktivitas fisik anak di sekolah sehingga lama waktu anak berada di sekolah tetap dianalisis dan menunjukkan tidak ada perbedaan lama sekolah antara anak gemuk dan tidak gemuk. Kelemahan yang kedua adalah tidak mengukur langsung fasilitas bermain atau kondisi sesungguhnya di lingkungan responden secara objektif sehingga penelitian selanjutnya perlu dilakukan pengukuran secara objektif untuk melihat kesesuaian antara persepsi orang tua dan kondisi di lapangan.

\section{SIMPULAN DAN SARAN}

Lama waktu bermain di luar rumah di bawah 2 jam berkontribusi terhadap kejadian kegemukan pada anak prasekolah di Kota Yogyakarta. Kegemukan juga dipengaruhi oleh kepadatan penduduk melalui penurunan lama waktu bermain anak di luar rumah. Anak prasekolah sebaiknya bermain di luar rumah setidaknya 90 menit per hari untuk menurunkan risiko kegemukan pada anak prasekolah. Orang tua sebaiknya mengajak anak untuk bermain aktif di luar rumah dengan memanfaatkan fasilitas yang ada di lingkungan.

Edukasi pada orang tua tentang bermain di luar rumah juga dapat disebarluaskan melalui pihak sekolah saat dilakukan pertemuan wali murid. Sekolah juga perlu mengadakan kegiatan untuk beraktivitas aktif di luar ruangan. Bagi pemerintah, perlu mengoptimalisasi pelaksanaan dan pelayanan terkait fasilitas lingkungan fisik seperti penyediaan fasilitas bermain dan memperhatikan kondisi lingkungan sosial seperti keamanan dan kenyamanan suatu lingkungan mengingat kegemukan dipengaruhi oleh kondisi lingkungan fisik melalui lama waktu bermain di luar rumah.

\section{Pernyataan konflik kepentingan}

Penulis menyatakan tidak ada konflik kepentingan dengan pihak-pihak yang terkait dalam penelitian ini.

\section{RUJUKAN}

1. Puska P, Nishida C, Porter D. Obesity and overweight. Global strategy on diet, physical activity and health. Geneva: WHO Media Centre; 2003.

2. Ramachandran A, Snehalatha C. Rising burden of obesity in Asia. Obesity 2010;2010.

3. Balitbangkes. Riset Kesehatan Dasar (RISKESDAS) 2013. Jakarta: Departemen Kesehatan RI; 2013.

4. Addesa DD, Addezio LD, Martone D, Censi L, Scanu A, Cairella G, et al. Dietary intake and physical activity of normal weight and overweight / obese adolescents. Hindawi Int J Pediatr 2010;2010:13-5.

5. Chan CMS, Deave T, Greenhalgh T. Obesity in Hong Kong Chinese preschool children: where are all the nurses? J Pediatr Nurs 2010;25(4):264-73.

6. Zenk SN, Powell LM. US secondary schools and food outlets. Health Place 2008;14(2):336-46.

7. Brockman R, Jago R, Fox KR. The contribution of active play to the physical activity of primary school children. Prev Med 2010;51(2):144-7.

8. Cradock AL, Kawachi I, Colditz G, Gortmaker SL, Buka SL. Neighborhood social cohesion and youth 
participation in physical activity in Chicago. Soc Sci Med 2009; 68(3):427-35.

9. Gill T. Nothing ventured: balancing risks and benefits in the outdoors. Prevention. England: English Outdoor Council; 2010 .

10. Burdette HL, S M, Whitaker RC, H MP. Neighborhood playgrounds, fast food restaurants, and crime : relationships to overweight in low-income preschool children. Prev Med (Baltim) 2004;38:57-63.

11. Carver A, Timperio A, Crawford D. Playing it safe: The influence of neighbourhood safety on children's physical activity - A review. Heal Place 2008;14:217-27.

12. Tolbert R, Brooks-gunn J, Mclanahan S. Young children in urban areas : Links among neighborhood characteristics, weight status, outdoor play, and television watching. Soc Sci Med 2011;72(5):668-76.

13. Dahl A, Stigsdotter UK, Cosco NG. Urban forestry \& urban greening adults' motivation for bringing their children to park playgrounds. Urban For Urban Green 2012;11(4):396-405.

14. Marino AJ, Fletcher EN, Whitaker RC, Anderson SE. Amount and environmental predictors of outdoor playtime at home and school: a cross-sectional analysis of a national sample of preschool-aged children attending Head Start. Health Place 2012;18(6):1224-30.

15. Stone MR, Faulkner GEJ. Outdoor play in children: associations with objectively-measured physical activity, sedentary behavior and weight status. Prev Med (Baltim) 2014;65:122-7. A

16. Gleave J, Cole-Hamilton I. A world without play : A literature review [Internet]. Revised Ja. Russell the journal of the bertrand russell archives. London: Play England; 2012.

17. Balitbangkes. Riset Kesehatan Dasar (RISKESDAS) 2010. Jakarta: Departemen Kesehatan RI; 2010.

18. Dinkes DIY. Profil kesehatan Daerah Istimewa Yogyakarta tahun 2012. DI Yogyakarta: Dinas Kesehatan Provinsi D.I Yogyakarta; 2013.

19. IAP. Indonesia most liveable city index 2011. Djonoputro B, Prasetyo I, Argo TA, Muljanto D, Muttaqin D, editors. Ikatan Ahli Perencanaan Indonesia. Jakarta: Ikatan Ahli Perencanaan Indonesia; 2009.

20. Widiyanto D, Rijanta R. Lingkungan kota layak anak ( child-friendly city ) berdasarkan persepsi orangtua di Kota Yogyakarta. Bumi Lestari J Environ 2013;12(2):211-6.

21. Kasjono HS, Yasril. Teknik sampling untuk penelitian kesehatan. Sleman: Graha Ilmu; 2009.

22. Grafova IB. Overweight children: assessing the contribution of the built environment. Prev Med (Baltim) 2008;47(3):304-8.

23. Ohri-vachaspati P, Lloyd K, Delia D, Tulloch D, Yedidia MJ. A closer examination of the relationship between children 's weight status and the food and physical activity environment. Prev Med (Baltim) 2013;57(3):162-7.

24. Anggraini S. Faktor risiko obesitas pada anak taman kanakkanak di Kota Bogor. Bogor: Institut Pertanian Bogor; 2008.

25. Dwyer GM, Hardy LL, Peat JK, Baur LA. The validity and reliability of a home environment preschool-age physical activity questionnaire ( Pre-PAQ ). Int J Behav Nutr Phys Act 2011;1-14.

26. Ding D. Neighborhood environment walkability scale youth ( NEWS-Y ). Parent Version 2009;213-8.

27. Gama A, Mour I, Padez C. Perceptions of neighborhood environments and childhood obesity : evidence of harmful gender inequities among Portuguese children. Health Place 2013;19:69-73.

28. Timperio A, Salmon J, Ball K. Evidence-based strategies to promote physical activity among children, adolescents and young adults: review and update. J Sci Med Sport 2004;7(1 Suppl):20-9.

29. Villanueva K, Giles-corti B, Bulsara M, Mccormack GR, Timperio A, Middleton N, et al. How far do children travel from their homes ? Exploring children 's activity spaces in their neighborhood. Health Place 2012;18(2):263-73.

30. Pastadita IKR. Faktor risiko obesitas antenatal dan postnatal pada anak 2 - 5 tahun di Kodya Yogyakarta. Yogyakarta: Universitas Gadjah Mada; 2011.

31. Kimbro RT, Brooks-Gunn J, McLanahan S. Young children in urban areas: links among neighborhood characteristics, weight status, outdoor play, and television watching. Soc Sci Med 2011;72(5):668-76.

32. Cleland V, Crawford D, Baur L. A prospective examination of children's time spent outdoors, objectively measured physical activity and overweight. Int J Obes 2008;32:168593.

33. Watanabe M, Nakamura K, Fukuda Y, Takano T. Association of parental and children behaviors with the health status of preschool children. Prev Med (Baltim) 2006;42(4):297-300.

34. Forsyth A, Oakes JM, Schmitz KH, Hearst M. Does residential density increase walking and other physical activity? Urban Stud 2007;44(4):679-97.

35. Oreskovic NM, Kuhlthau KA, Romm D, Perrin JM. Built environment and weight disparities among children in highand low-income towns. Acad Pediatr 2009;9(5):315-21.

36. Lavin Fueyo J, Totaro Garcia LM, Mamondi V, Pereira Alencar G, Florindo AA, Berra S. Neighborhood and family perceived environments associated with children's physical activity and body mass index. Prev Med (Baltim) 2015;82:35-41.

37. Haese SD, Timperio A, Veitch J, Cardon G, Dyck D Van, Salmon J. Neighborhood perceptions moderate the 
association between the family environment and children 's objectively assessed physical activity. Health Place 2013;24:203-9.

38. Christian H, Giles-corti B, Knuiman M, Timperio A, Foster S. The influence of the built environment, social environment and health behaviors on body mass index. Results from RESIDE. Prev Med (Baltim) 2011;53(12):57-60.

39. Foster S, Knuiman M, Hooper P, Christian H, Giles-Corti B. Do changes in residents' fear of crime impact their walking? longitudinal results from RESIDE. Prev Med (Baltim) 2014;62:161-6.
40. Tandon P, Grow HM, Couch S, Glanz K, Sallis JF, Frank $\mathrm{LD}$, et al. Physical and social home environment in relation to children's overall and home-based physical activity and sedentary time. Prev Med (Baltim) 2014;66:39-44.

41. HulstA Van, Gauvin L, Kestens Y, Barnett TA. Neighborhood built and social environment characteristics : a multilevel analysis of associations with obesity among children and their parents. Int J Obes 2013;37(10):1328-35.

42. Foster S, Villanueva K, Wood L, Christian H, Giles-corti B. The impact of parents' fear of strangers and perceptions of informal social control on children 's independent mobility. Health Place 2014;26:60-8. 